\title{
OS CONCEITOS DE FOUCAULT E ANÁLISESDAS RELAÇÕES DE TRABALHO DOS PESCADORES ARTESANAIS DA VILA DO TREME - UNIDADE DE CONSERVAÇÃO DA RESEX CAETÉ-TAPERAÇU
}

\author{
Roseli da Silva Cardoso \\ Fátima Cristina da Costa Pessoa ${ }^{2}$
}

\begin{abstract}
RESUMO
O empreendimento analítico deste estudo situa-se na Lei 9.985 de 18 de julho de 2000, a qual institui o Sistema Nacional de Unidades de Conservação- SNUC. O espaço analisado compreende duas unidades de conservação, a vila do Treme (Resex Caeté-Taperaçu) e a vila do Araí (Resex AraíPeroba), a partir da análise discursiva dos embates sociais nas referidas comunidades, na tensão entre o discurso tradicional dos pescadores artesanais e o discurso institucional dos representantes governamentais que incidem diretamente nas relações de trabalho da pesca artesanal. Pressupõe-se que tais relações se estabelecem por lutas de forças entre saberes e poderes, as quais não podem ser vistas como um objeto natural, mas sobretudo como um processo dinâmico e heterogêneo em constante transformação, como uma prática discursiva.
\end{abstract}

Palavras-chave: Linguagem. Saberes. Trabalho. Tradicional.

\begin{abstract}
The analytical enterprise of this study is situated in Law 9.985 of July 18, 2000, which constitutes the National System of Conservation Units - SNUC. The area analyzed comprises two conservation units, the village of Treme (Resex Caeté-Taperaçu) and the village of Araí (Resex Araí-Peroba), starting on the discursive analysis of the social conflicts in these communities, on the tension between the traditional discourse of artisanal fishermen and the institutional discourse of government representatives that directly affect the work relations of artisanal fishing. It is assumed that such relations are established by power struggles between knowledge and power, which can not be seen as a natural object, but above all as a dynamic and heterogeneous process in constant transformation, as a discursive practice.
\end{abstract}

Keywords: Language. Knowledge. Work. Traditional.

\section{INTRODUÇÃO}

Este artigo traz uma das análises empreendidas na tese (em andamento), intitulada ' $A$ interface linguagem, discurso e trabalho nas relações entre os pescadores artesanais $e$ representantes de instituições governamentais da pesca ${ }^{3}$. Trata-se da análise discursiva da Lei 9.985 de 18 de julho de 2000, a qual institui o Sistema Nacional de Unidades de

\footnotetext{
${ }^{1}$ Este artigo está relacionado à minha pesquisa de doutorado, intitulada 'A interface linguagem, discurso e trabalho nas relações entre os pescadores artesanais e representantes governamentais da pesca', do Programa de Pós-Graduação em Letras- PPGL- UFPA-Belém. E-mail: roselicrds008@ gmail.com.

${ }^{2}$ Professora doutora do Programa de Pós-Graduação em Letras - PPGL -UFPA - Belém. Pesquisadora em estudos linguísticos com ênfase em análise do discurso. E-mail: fpessoa37@gmail.com.

${ }^{3}$ Qualificação da tese realizada no dia 05 de fevereiro de 2019, avaliada e aprovada pelo professor Dr. José Guilherme dos Santos Fernandes e pela professora Dr ${ }^{a}$ Ivânia dos Santos Neves.
} 
Conservação- SNUC. Com ênfase nas relações enunciativas que incidem direta ou indiretamente nas relações de trabalho da pesca artesanal, com base na Análise do Discurso francesa. Assim, tem-se fundamentação nos conceitos de formação discursiva, regularidades enunciativas, raridade, acúmulo e exterioridade em Foucault (2012), postulados na obra Arqueologia do saber, juntamente com a obra Microfísica do poder (2013), com sua importante contribuição para se refletir sobre as estratégias do poder e sua eficácia produtiva para manter uma positividade. Por fim a obra A ordem do discurso (1996), com os princípios de ordenamento, de exclusão, de rarefação do discurso e a genealogia da formação discursiva.

Metodologicamente, realizou-se coleta de dados por meio de gravação das narrativas dos pescadores e dos representantes das instituições governamentais ligadas à pesca artesanal, material primário de análise, nosso objeto de estudo na constituição do corpus desta pesquisa. Além disso, tem-se o material secundário de grande importância, como os documentos referentes à deliberação de demandas políticas e sociais direcionadas ao sujeito da pesca artesanal, relacionados à criação, implantação e gestão da RESEX. Assim, a unidade de análise para este estudo corresponde ao material documental da pesquisa, com profunda incidência nas relações de trabalho da pesca artesanal, nas duas Unidades de Conservação, a vila do Treme, Bragança-PA e vila do Araí, Augusto Correa-PA.

\section{UM SISTEMA DE DISPERSÃO NAS RELAÇÕES DE SABER E PODER DA PESCA ARTESANAL}

Para a análise discursiva das relações de saber e poder a partir de Foucault (2012), a priori deve-se estudar formas de repartição, em vez de se constituir cadeias de inferências. Em outros termos, em lugar de estabelecer quadros de diferenças em analogia aos linguistas, o analista do discurso deve descrever sistemas de dispersão e estudar as regularidades enunciativas, as condições de existência de uma repartição discursiva dada, a partir dos conceitos de formação de objetos, modalidades de enunciação, formação de conceitos, escolhas temáticas ou formação de estratégias. Tais conceitos abrem espaço para empreendermos uma arqueologia do saber em que se enquadra nosso objeto de estudo. Em conformidade com as reflexões de Foucault,

Por sistema de formação é preciso, pois, compreender um feixe complexo de relações que funcionam como regra: ele prescreve o que deve ser correlacionado em uma prática discursiva, para que esta se refira a tal ou tal objeto, para que empregue tal ou tal enunciação, para que utilize tal ou tal conceito, para que organize tal ou tal estratégia. Definir em sua individualidade singular um sistema de formação é, 
caracterizar um discurso ou um grupo de enunciados pela regularidade de uma prática. (FOUCAULT, 2012, p.83).

Nessa perspectiva, a noção de genealogia do poder em Foucault $(1996,2003)$ também constitui um dos conceitos fundamentais para este estudo, uma vez que a tensão das relações de saber e poder se constituem por meio de dispositivos ${ }^{4}$ de natureza essencialmente estratégica, mediante o entrecruzamento de diferentes sujeitos enunciadores no mesmo campo discursivo. Segundo o referido autor, dispositivo seria os vários mecanismos pelos quais o poder se inscreve nas relações sociais, dada sua constituição heterogênea, circula tanto por entre as redes institucionais mais complexas, vinculadas ou não ao Estado, quanto pelas relações mais próximas do convívio familiar.

Neste sentido, pode-se falar de uma análise arqueogenealógica no contexto da pesca artesanal, a qual possibilita o analista do discurso adentrar no jogo de uma exterioridade, isto é, no conjunto das coisas ditas nas relações de saber e poder, regularidades enunciativas, transformações e entrecruzamentos verificáveis que indicam o lugar singular de um sujeito falante situado no tempo e no espaço socialmente definidos. Nesta perspectiva, o discurso "não é simplesmente aquilo que traduz as lutas ou os sistemas de dominação, mas aquilo por que, pelo que se luta, o poder do qual nos queremos apoderar” (FOUCAULT, 1996, p.10).

A partir da relação entre desejo e poder, apontadas pelo autor, vê-se que as estratégias do poder são eficazes na produção de domínios de objetos e rituais de verdade e estão intrinsecamente ligadas à constituição do saber. Do ponto de vista enunciativo, o saber se coloca em campos de utilização na delimitação da relação entre: a) aquilo do que se pode falar em uma prática discursiva (o domínio dos objetos); b) o espaço em que o sujeito está situado para falar dos objetos (posição subjetiva); c) o campo de coordenação e de subordinação dos enunciados, em que os conceitos aparecem, são definidos, aplicam-se e se transformam; d) as possibilidades de utilização e de apropriação dos discursos, segundo Castro (2009, p. 394).

Portanto, nesse jogo enunciativo entre o discurso tradicional e institucional "não há saber neutro" ou "o saber não deve ser visto fora das relações de poder que o constituem", assertivas confirmadas nas palavras de Machado (2013), na introdução da obra Microfísica do poder. Ele diz ainda que "o fundamental é que saber e poder se implicam mutuamente: não há relação de poder sem constituição de um campo de saber, como também, reciprocamente,

\footnotetext{
${ }^{4} \mathrm{O}$ conceito de dispositivo foi ampliado por dois filósofos da atualidade, Agamben e Deleuze. Para o propósito deste estudo, a definição de Agamben nos ajuda a pensar as relações de saber e poder dos diferentes enunciadores no campo discursivo da pesca artesanal. Ele afirma ser um dispositivo “(...) qualquer coisa que tenha de algum modo a capacidade de capturar, orientar, determinar, interceptar, modelar, controlar e assegurar os gestos, as condutas e as opiniões dos seres viventes." (AGAMBEN, 2009, p.40).
} 
todo saber constitui novas relações de poder", assim conclui que "todo ponto de exercício do poder é, ao mesmo tempo, um lugar de formação de saber” (FOUCAULT, 2013, p. XXI).

Nessa abordagem arqueogenealógica, o poder deve dar conta da constituição dos saberes, por meio de discursos e domínios de objetos, nas condições de possibilidades no interior de uma trama histórica, isso significa livrar-se do sujeito constituinte, transcendente com relação aos acontecimentos, deixar de perseguir sua identidade vazia ao longo da história. Mas também, livrar-se da noção negativa, esquelética e repressiva do poder, o qual se identifica com o poder da lei que diz não, a força da proibição. Em conformidade com Foucault (2003, p.8), o poder deve ser considerado como "uma rede produtiva que atravessa todo corpo social muito mais do que uma instância negativa que tem por função reprimir”, e sobretudo o poder "produz coisas, induz ao prazer, forma saber, produz discurso", fato que configura uma nova "economia" do poder".

Desse modo, justifica-se o espaço a ser descrito neste estudo como um sistema de dispersão interdiscursivo, inscrito na tensão das relações de saber e poder, uma vez que nele encontram-se dispositivos, conforme Foucault (2013), "sempre inscritos num jogo de poder, estando sempre, no entanto, ligado a uma ou a configurações de saber que dele nascem, mas que igualmente o condicionam". O autor diz ainda que "dispositivos são estratégias de relações de força sustentando tipos de saber e sendo sustentadas por eles." (FOUCAULT, 2013, p. 246). Daí a necessidade de analisar a lei na irrupção dos acontecimentos discursivos e na dispersão temporal no contexto da pesca artesanal.

\section{A LEI NO ESPAÇO DISCURSIVO DA PESCA ARTESANAL}

Da unidade de análise no espaço discursivo da pesca artesanal, a Lei 9.985, de 18 de julho de 2000, a qual estabelece critérios e normas para criação, implantação e gestão das Unidades de Conservação (UC) da RESEX, questiona-se: quem são os sujeitos que enunciam essa lei? Quais interesses ela representa na ordem social? A quem ela se destina? Como essa prática discursiva se insere no lugar da tradição?

\footnotetext{
${ }^{5}$ Ressalta-se o desbloqueio tecnológico da produtividade do poder que ocorreu a partir dos séculos XVII e XVIII, em que as monarquias da época clássica não só desenvolveram grandes aparelhos de Estado, como o exército, polícia, administração local - destaque na obra Vigiar e punir - mas instauraram o que Foucault chama de "nova 'economia' do poder, a qual se efetiva por meio de procedimentos que permitem circular os efeitos de poder de forma ao mesmo tempo contínua, ininterrupta, adaptada e 'individualizada' em todo corpo social" (FOUCAULT, 2003, p.8).
} 
Em outros termos, propõe-se compreender qual é o lugar desse saber no confronto com o saber dos pescadores artesanais, mas sobretudo perceber o lugar do sujeito da tradição na constituição do poder do Estado nas UC. Posto que a referida lei o representa por meio do viés discursivo do Estado, apesar de ser constituída sem a participação dos sujeitos da pesca, interferindo diretamente em seu modo de vida, em especial nas suas relações de trabalho.As regularidades discursivas de análise correspondem ao embate entre o discurso tradicional e o discurso institucional jurídico, na constituição das relações de saber e poder a partir dos sujeitos que os representam: os pescadores artesanais e os representantes governamentais da RESEX.

A partir de uma leitura analítica discursiva, logo no capítulo I - Das disposições preliminares desta lei, encontra-se a ausência da participação das comunidades que povoam as áreas que serão demarcadas e protegidas, pois é dada ao poder público total autoridade na instituição das Unidades de Conservação, ou melhor, aos representantes do Estado, destacado na regularidade da referida lei, conforme art. $2^{\circ}$ :

\footnotetext{
I- Unidade de conservação: espaço territorial e seus recursos ambientais, incluindo as águas jurisdicionais com características naturais relevantes, legalmente instituído pelo poder público. Com objetivos de conservação e limites definidos, sob o regime especial de administração, ao qual se aplicam garantias adequadas de proteção.
}

Esta materialidade da lei vista pelo viés discursivo, de acordo com Foucault (2013), é um exemplo de eficácia e de estratégias produtivas do poder, cujo objetivo, por mais que tenha um fundo conservacionista dos recursos naturais e uso sustentável, é manter uma positividade, pois o poder público produz domínio de objetos e rituais de verdades, quando instituída legalmente sua autoridade de criar as UC. Portanto, vê-se implicada na ordem discursiva da lei, a negação da participação dos sujeitos da pesca artesanal e moradores das comunidades tradicionais, uma vez que na afirmação desse enunciado se ressalta a autoridade do poder público por meio das condições de produção enunciativa referente à criação das UC, autoridade sustentada pelas 'garantias adequadas de proteção', sem a participação dos moradores do 'espaço territorial e seus recursos ambientais, incluindo as águas jurisdicionais com características naturais relevantes'.

Trata-se de estratégias produtivas do Estado que têm a função de excluir, oprimir, recalcar e mascarar os sujeitos da tradição sem o uso da força ou repressão, implicadas na materialidade discursiva de criação das UC prevista na lei. Já que os moradores das comunidades não têm nenhuma participação, apenas o direito de receberem informações 
acerca das decisões dos representantes governamentais. Nota-se que há um funcionamento discursivo, no qual os sujeitos que enunciam a lei são os representantes do Estado e os sujeitos que não enunciam são os sujeitos moradores das UC.

Nesse sentido, na ordem do discurso se observa a exclusão dos saberes das comunidades tradicionais na criação das UC, pois na medida que a leitura da materialidade da lei avança, observa-se que os sujeitos residentes nas UC apenas serão informados pelo poder público, com base nos estudos técnicos e consulta pública, das decisões tomadas para identificar a localização, dimensão e os limites das UC, mediante regulamento. Segundo disposto no capítulo IV que trata das normas para a implantação, criação e gestão da UC, no art. 22, legitima-se a precedência de estudos técnicos:

$\S 2^{\underline{0}}$ A criação de uma unidade de conservação deve ser precedida de estudos técnicos e de consulta pública que permitam identificar a localização, a dimensão e os limites mais adequados para a unidade, conforme se dispuser em regulamento.

$\S 3^{\circ}$ No processo de consulta de que trata o $\S 2^{\underline{o}}$, o Poder Público é obrigado a fornecer informações adequadas e inteligíveis à população local e a outras partes interessadas.

Ao tratar de interdiscurso no campo discursivo jurídico destacado no jogo de presença verso ausência enunciativas, nota-se o interdito na regularidade discursiva da lei. Tem-se a exclusão dos saberes dos sujeitos tradicionais, uma heterogeneidade constitutiva nas relações de trabalho da pesca artesanal. Assim, os estudos técnicos são considerados os saberes ditos 'adequados e inteligíveis' que fundamentam as decisões do poder público, saberes que se tornam legítimos mediante regulamento. Nesse aspecto, os saberes tradicionais, não ditos, inadequados e não inteligíveis, indizíveis pelo simples fato de existirem outros saberes legítimos ditos na materialidade enunciativa da lei.

Isto confere valor de verdade a um saber constituído em outro lugar institucional, fora do espaço da pesca artesanal, distante do lugar da tradição, segundo regularidade disposta no $\S 2^{\circ}$ - 'A criação de uma unidade de conservação deve ser precedida de estudos técnicos e de consulta pública...”, mais ainda no $\S 3^{\circ}$ - 'o Poder Público é obrigado a fornecer informações adequadas e inteligíveis à população local e a outras partes interessadas'. Portanto, nas condições de apropriação e utilização dos enunciados destacados no capítulo IV, art. 22 da Lei 9.985, não há apenas a exclusão e ausência dos saberes e dos sujeitos da tradição, mas sobretudo, vê-se uma prática discursiva que institui outros saberes, os estudos técnicos com valor de verdade no espaço discursivo das comunidades tradicionais. Um exemplo do 
postulado de Foucault (2003),em que “o exercício do poder cria perpetuamente saber e, inversamente, o saber acarreta efeitos de poder".

Com base no jogo enunciativo acima, pode-se afirmar que toda relação de saber e poder se estabelece por meio de verdades constituídas em rede interdiscursivas que, hierarquicamente, configura as posições dos sujeitos na ordem discursiva. Nesse sentido, os detentores do saber que possui valor de verdade legitimado pela lei, não são os pescadores no contexto da pesca artesanal nem os moradores das UC, mas os representantes governamentais e sua equipe técnica, uma vez que por meio de seus estudos são autorizados a 'identificar a localização, a dimensão e os limites mais adequados para a unidade, conforme se dispuser em regulamento'.

É válido ressaltar o processo de realocação dos moradores de UC, onde alguns foram indenizados e proibidos de habitar em determinadas áreas por meio de parecer do poder público. O reassentamento das populações de áreas protegidas, perante à lei, é estabelecido por meio de acordo entre as partes, dispositivo de desapropriação marcado por tensão e conflitos em âmbito internacional e nacional ${ }^{6}$. De acordo com a materialidade instituída no art. 42, destacado abaixo:

Art. 42. As populações tradicionais residentes em unidades de conservação nas quais sua permanência não seja permitida serão indenizadas ou compensadas pelas benfeitorias existentes e devidamente realocadas pelo Poder Público, em local e condições acordados entre as partes.

Nessa hierarquização de poder e saber, os interesses dos sujeitos da tradição são apagados e ignorados na ordem discursiva prevista em lei no art. 42. O interdito expresso na lei interpela o sujeito da tradição, tem-se o assujeitamento mascarado por indenização, compensação e benfeitorias do poder público, um dispositivo que garante os interesses dos sujeitos que representam o Estado. Dito isto, vale ressaltar dois questionamentos: que espécie de indenização ou bem feitorias existentes podem compensar a perda do lugar da tradição e a memória de uma vida inteira construída com seus antepassados? Quais as condições desse acordo entre as partes se ao poder público é dada total autoridade de decisão?

Em outros termos, os moradores das UC, mediante cadastramento nacional, possuem apenas o direito de uso sustentável dos recursos naturais a partir de um plano de manejo, no qual lhes foi concedido o direito de participação na sua elaboração e gestão, de acordo com o

\footnotetext{
${ }^{6}$ A esse respeito, Diegues (2001, p. 114) afirma que "tanto aqui como lá, o objetivo é conservar uma área "natural" contra os avanços da sociedade urbano-industrial, sem se atentar para o fato de grande parte dessas "áreas naturais" estarem sendo habitadas por populações que nada têm de "modernas" e "tecnológicas". Ao contrário, em sua maioria são populações que vivem de atividades de subsistência, com fracas vinculações com o mercado e com pequena capacidade de alteração significativa dos ecossistemas".
} 
art. 27, do Capítulo IV da Lei 9. 985, de 18 de junho de 2000, o qual assegura a ampla participação da população residente. Conforme disposto no $\S 2^{\circ}$ da referida lei:

$\S 2^{\circ}$ Na elaboração, atualização e implementação do Plano de Manejo das Reservas Extrativistas, das Reservas de Desenvolvimento Sustentável, das Áreas de Proteção Ambiental e, quando couber, das Florestas Nacionais e das Áreas de Relevante Interesse Ecológico, será assegurada a ampla participação da população residente.

Tais questionamentos se justificam porque a materialidade da lei, de certa forma, impõe a institucionalização dos sujeitos da tradição para atender interesses de representantes políticos e econômicos no campo discursivo da pesca, regularidade expressa no art. 50, referente à organização e manutenção de cadastro nacional de UC, o qual constitui poder às três esferas do poder público: esfera federal - Ministério do meio ambiente; esfera estadual Ibama e órgãos estaduais; esfera municipal - representantes do prefeito e instituições municipais da secretaria de meio ambiente, etc. Conforme regularidade discursiva abaixo:

Art. 50. O Ministério do Meio Ambiente organizará e manterá um Cadastro Nacional de Unidades de Conservação, com a colaboração do Ibama e dos órgãos estaduais e municipais competentes.

Na materialidade da lei, a utilização dos verbos 'organizará e manterá' legitimam os sujeitos representantes do Ministério do Meio Ambiente, órgãos municipais e estaduais e colabores, a aplicação do dispositivo do poder no espaço discursivo das comunidades tradicionais, por meio da institucionalização dos moradores de UC. Fato que acarreta interdição e exclusão daqueles que não se enquadram às exigências do sistema de Cadastro Nacional, de um lado. Por outro, possibilita a inserção daqueles (falsos moradores) que visam apenas garantir o privilégio de representar a comunidade ou receber os benefícios financeiros destinados à população residente nas áreas protegidas.

Portanto, tem-se uma função enunciativa que se inscreve na distribuição desigual de lugar, funções e papéis dos sujeitos, ou seja, a organização prevista em lei considera o lugar da tradição como o lugar da desordem e configura o apagamento da identidade e status dos sujeitos representantes do discurso tradicional. Em contrapartida, legitima o lugar da organização dos representantes governamentais, mantém sua identidade e status no estabelecimento dos critérios e manutenção de cadastro nacional. Trata-se de uma rede discursiva em prol da institucionalização dos sujeitos da tradição, marcada por campos de utilização de enunciados que selecionam, identificam, legitimam, incluem ou excluem sujeitos na conjuntura social das UC, uma relação de saber e poder que demarca as posições dos sujeitos enunciativos no espaço discursivo da pesca artesanal. 


\section{CONSIDERAÇÕES FINAIS}

O embate entre o discurso tradicional e o discurso institucional se constitui na relação de saber e poder como qualquer outra na sociedade, onde a exclusão não pode ser pensada apenas na oposição razão e loucura, mas nas diversas formas de controle do discurso, uma certa rarefação do discurso, pois, em relação aos sujeitos que falam, Foucault (1996, p. 37) propõe que "ninguém entrará na ordem do discursos e não satisfazer a certas exigências ou se não for, de início, qualificado para fazê-lo". Logo, os sujeitos qualificados são os representantes governamentais nesta ordem discursiva.

Na verdade, a lei analisada é um dispositivo do poder, um certo controle dos discursos que determinam as condições de seu funcionamento na exterioridade da pesca artesanal, impondo regras de formação e seleção dos sujeitos que falam. Esta é a tarefa das novas instituições: a Resex produz efeitos de poder localmente constituídos em engrenagens de saber, uma vontade de verdade, potencialmente distribuída e imposta no espaço das comunidades tradicionais, de certo modo, os efeitos da lei não interferem apenas o saber fazer nas relações de trabalho, mas afetam também os bens simbólicos e culturais dos sujeitos da tradição.

\section{REFERÊNCIAS}

AGAMBEN, Giorgio. O que é contemporâneo? e outros ensaios. Chapecó, SC: Agros, 2009.

BRASIL. 2000. Lei $\mathbf{n}^{\mathbf{0}}$ 9985, de 18 de julho de 2000. Institui o Sistema Brasileiro de Unidades de Conservação - SNUC.

BRASIL. Decreto de 20 de maio de 2005. Dispõe sobre a criação da Reserva Extrativista Marinha de Araí-Peroba, no Município de Augusto Corrêa, no Estado do Pará, e dá outras providências. Brasília, DF, 2005.

CASTRO, Edgardo. Vocabulário de Foucault: um percurso pelos seus temas, conceitos e autores. Tradução Ingrid Müller. Revisão técnica Alfredo Veiga-Neto e Walter Omar Kohan. Belo Horizonte: Autêntica Editora, 2009.

FOUCAULT, Michel. Microfísica do poder. $27^{\mathrm{a}}$ ed. - São Paulo: Graal, 2013.

FOUCAULT, Michel. A arqueologia do saber. $7^{\mathrm{a}}$ ed. Rio de Janeiro: Forense Universitária, 2012.

FOUCAULT, Michel. Vigiar e punir: o nascimento da prisão. 41 a ed. Petrópolis, RJ: Vozes, 2003.

FOUCAULT, Michel. A ordem do discurso. São Paulo: Loyola, 1996. 
FURTADO, Lourdes Gonçalves. Ocupação Humana do litoral Amazônico- Belém, Museu Paraense Emílio Goeldi, 2001.

FURTADO, Lourdes Gonçalves. Povos das águas: realidade e perspectiva na Amazônia. In: Furtado, Lourdes Gonçalves; LEITÃO, Wilma; MELLO, Alex Fiuza (orgs.). Belém: Museu Paraense Emílio Goeldi, 1993.

DIEGUES, Antônio Carlos S. Conhecimento tradicional e apropriação social do ambiente marinho. 2004. Disponível em: http:www.usp.br/nupaub/. Acesso em 06 maio 2014.

DIEGUES, Antônio Carlos S. O mito moderno da natureza intocada. $3^{\text {a }}$ ed. Editora: Hucitec, São Paulo, 2001.

Recebido em: 24/10/2019 Aprovado em: 15/11/2019 